\title{
La descentralización administrativa en Colombia: un reto inconcluso y un desafío para el posconflicto*
}

\author{
Hugo Alejandro Sánchez Hernández \\ Recibido: 15 de mayo de 2016 • Aprobado: 10 de junio de 2016
}

\section{Resumen}

Colombia es un país que cuenta con una férrea tradición centralista desde la Constitución de 1886, atemperada en buena medida con la expedición de la Carta Política de 1991, que consagró los conceptos de descentralización administrativa y autonomía de las entidades territoriales. Sin embargo, pese a ello, después de veinticinco años de su expedición, el anhelo de los constituyentes de hacer una Colombia más equilibrada, en cuanto a poder de decisión, y, a su vez, más cercana a las verdaderas necesidades de la población es aún un reto inconcluso. En ese sentido, esta reflexión pretende demostrar cómo la ausencia del Estado en los territorios más alejados del centro del poder político, económico y social ha sido una de las consecuencias directas del conflicto armado interno que vive nuestro país, situación que le plantea al Estado un importante desafío frente a una eventual situación de posconflicto.

Palabras clave: Autonomía de las entidades territoriales, conflicto armado, descentralización administrativa, situación de posconflicto.

^ El presente artículo es resultado de la producción académica generada por el convenio suscrito entre la Universidad Santo Tomás (Sede Bogotá) y la Universidad Carlos III de Madrid. El proyecto de investigación al que se adscribe el presente artículo es "Los retos de la Constitución y la administración frente a la paz y la seguridad ciudadana”. DOI: http://dx.doi.org/10.15332/s1900-0448.2016.0045.04

${ }^{*}$ D Doctor en Derecho Público de la Universidad Carlos III de Madrid, España. Especialista en Derecho Administrativo (D.S.U.) y Magister (D.E.A.) en Ciencias Administrativas de la Universidad Paris II - Panthéon Assas, Francia. En la actualidad es tutor investigador de la Maestría en Derecho Público de la Universidad Santo Tomás de Bogotá. Así mismo, es docente de posgrado en las Universidades del Rosario, Sergio Arboleda, Los Andes, La Sabana, Libre de Cali y Santo Tomás en sus diferentes sedes. Ha sido profesor invitado de la Universidad Montesquieu - Bordeaux IV, Francia. Correo electrónico: hugosanchez@usantotomas.edu.co 


\title{
Administrative decentralization in Colombia: AN UNFINISHED CHALLENGE AND A CHALLENGE FOR THE POST-CONFLICT
}

\begin{abstract}
Colombia is a country with a strong centralist tradition since the proclamation of the Constitution of 1886, which was only regulated and brought under control with the Constitution of 1991; which established the concepts of administrative decentralization and autonomy of local authorities. However, despite this, after 25 years of being issued, the intention of the Constituency to make a more balanced Colombia, when it comes to decision-making power, and closeness to general population's needs; are still unreached challenges. In this regard, those theoretical considerations aim to show how the absence of the state forces in most remote areas, the ones far away from the political, economic and social power epicenter, has been one of the direct consequences of the internal armed conflict in our country, which from several points of view, is still an issue for the state considering an eventual post-conflict.
\end{abstract}

Keywords: Autonomy of local authorities, armed conflict, administrative decentralization, post-conflict situation.

\section{A descentralização administrativa na Colômbia: um DESAFIO INCONCLUSO E UM DESAFIO PARA O PÓS-CONFLITO}

\section{Resumo}

A Colômbia é um país com uma férrea tradição centralista desde a Constituição de 1886, temperada, até certo ponto, com a expedição da Carta Política de 1991 que consagrou os conceitos de descentralização administrativa e autonomia das entidades territoriais. Porém, a pesar disso, depois de vinte e cinco anos da sua expedição o almejo dos constituintes por fazer uma Colômbia mais equilibrada, no relacionado com o poder de decisão, e ao mesmo tempo, mais próxima das verdadeiras necessidades da população é ainda um desafio inconcluso.

Neste sentido, esta reflexão procura demonstrar como a ausência do Estado nos territórios mais afastados do centro do poder político, econômico e social tem sido uma das consequências diretas do conflito armado interno que vive nosso país, 
situação que apresenta ao Estado um importante desafio numa eventual situação de pós-conflito.

Palavras-chave: Autonomia das entidades territoriais, conflito armado, descentralização administrativa, situação de pós-conflito.

\section{Introducción}

Luego de dos procesos de paz fallidos con la guerrilla de las FARC -el primero iniciado a mediados de los años ochenta del siglo pasado en el Gobierno de Belisario Betancur Cuartas (1982-1986), denominado Pactos de La Uribe (Centro de Memoria, Paz y Reconciliación, s. f. a), y el segundo, a finales de la década de los noventa, bajo la presidencia de Andrés Pastrana Arango (1998-2002), conocido como las Negociaciones del Caguán (Centro de Memoria, Paz y Reconciliación, s. f. a)-, así como múltiples negociaciones reservadas sostenidas en los dos gobiernos de Álvaro Uribe Vélez (2002-2010), que concluyeron insatisfactoriamente por diversas razones de índole político y militar, llevaron finalmente a que a mediados del primer periodo presidencial del presidente Juan Manuel Santos Calderón (20102018), el 23 de septiembre de 2012, luego de sucesivas negociaciones secretas entre las partes concernidas por el conflicto interno, se inaugurara formalmente la mesa de negociaciones, en La Habana y Oslo, ciudades pertenecientes a los países mediadores, Cuba y Noruega, respectivamente. Este ha sido un proceso que, aunque por momentos ha tenido dificultades y altibajos, ha gozado de la esperanza de los ciudadanos para que se acabe con la barbarie del conflicto armado que ha devastado el país por más de cincuenta años ${ }^{1}$.

\footnotetext{
${ }^{1}$ Hasta antes de la entrega del presente artículo, en la mesa de conversaciones de La Habana, Cuba entre el Gobierno de Colombia y los representantes de las FARC E. P. se había logrado el acuerdo en cuatro de los seis puntos del Acuerdo General, a saber: i) política de desarrollo agrario integral; ii) participación política; iii) solución al problema de las drogas ilícitas; iv) víctimas. Restaban por discutir los puntos sobre v) fin del conflicto, vi) implementación, verificación y refrendación. De otra parte, el 15 de diciembre del año 2015, las partes publicaron un borrador conjunto del Acuerdo sobre las Víctimas del Conflicto: "Sistema Integral de Verdad, Justicia, Reparación y No Repetición, incluyendo la Jurisdicción Especial para la Paz; y Compromiso sobre Derechos Humanos”, en el que se establece una jurisdicción especial para la paz y, a su vez, un entramado de instituciones (Comisión para el Esclarecimiento de la Verdad, la Convivencia y la No Repetición y la Unidad para la Búsqueda de Personas dadas por Desaparecidas en el contexto y en razón del conflicto) y medidas para soportar, adecuar y blindar la terminación del conflicto armado interno en Colombia. Fuente: https://www. mesadeconversaciones.com.co
} 
Colombia, para bien o para mal, es un país con una larga tradición de negociaciones de paz con grupos insurgentes, una de ellas, quizás la más recordada, fue la que sostuvo el gobierno del entonces presidente César Gaviria Trujillo con las guerrillas del M-19, el EPL y el Quintín Lame, la cual sirvió, a su vez, como caldo de cultivo para la movilización proreforma que apuró la instalación de una Asamblea Nacional Constituyente, que el 7 de julio de 1991 promulgó la nueva Constitución Política de la República de Colombia, la que, a su vez, reemplazó la antiquísima Constitución de 1886, que capitaneó los destinos de la joven república por más de un siglo, y sobre la cual atinaremos a decir inicialmente que era de origen conservador, confesional, presidencialista, unitarista y altamente centralizadora (Manrique, 2010, pp. 67-68).

Es decir, la tradición de un Ejecutivo fuerte y de la toma de decisiones desde su capital, Bogotá, o lo que es lo mismo, desde el centro del país, no es cosa nueva, y su raigambre es tan honda en nuestro derecho y en nuestra cultura que, aún con el cambio de modelo que supuso la Constitución Política de 1991, no se ha logrado superar el amaño a las ya ancestrales tradiciones jurídico-políticas centralistas.

En la Carta Política de 1991 se proclamó que Colombia es un "Estado social de Derecho" (Constitución Política de Colombia de 1991, art. 1.o) bajo la fórmula de república "unitaria, descentralizada y con plena autonomía de sus entidades territoriales" (Ídem.), es decir, la nueva república nació con un corte típicamente presidencialista, con un único centro de impulsión política: el Congreso de la República, pero atemperado por las facultades autónomas y descentralizadas de que gozan las entidades territoriales. Esto en teoría, ya que, como veremos más adelante, en la práctica el anhelo de los constituyentes de hacer una Colombia más equilibrada en cuanto a poder de decisión y, a su vez, más cercana a las verdaderas necesidades de la población es aún un reto inconcluso.

Empero, este es un reto pendiente con profundas consecuencias jurídicas, económicas, políticas y sociales. La principal de ellas, y esta es nuestra hipótesis, es el conflicto armado interno, el cual en buena medida se ha acrecentado debido a la ausencia del Estado en los territorios más alejados del centro del poder político, en tanto que tenemos unos municipios y departamentos débiles económica y políticamente, que responden a los vestigios del centralismo de la Constitución de 1886, que apenas participan de las rentas nacionales, que además vieron centralizada la administración de las regalías producto de la exploración, explotación o transporte de los recursos naturales no renovables con la expedición del Acto Legislativo 05 
del 18 de julio de $2011^{2}$ y que han visto truncada su expansión económica debido a la concentración de la actividad económica e industrial en la superpoblada capital del país y en algunas ciudades intermedias. Esto también ha ocurrido porque en la jurisdicción de las entidades territoriales muchas veces hacen más presencia los grupos al margen de la ley que el mismo Estado, todo ello aunado a la concentración de la tierra en manos de grandes terratenientes del país y otras múltiples causas que han desembocado en este conflicto fratricida que ha cobrado millones de víctimas y un enorme gasto público militar ${ }^{3}$.

Así las cosas, vale la pena preguntarse: ¿la centralización político-administrativa es una de las causas del conflicto armado en Colombia? De otra parte, ¿es Colombia una verdadera república descentralizada administrativamente?

Con el fin de resolver estas inquietudes, (1) hemos decidido tratar en una primera instancia las teorías jurídicas sobre las formas de Estado y el modelo de Estado en Colombia; (2) revisaremos a continuación el concepto de centralización política y descentralización administrativa, así como su implantación en nuestro modelo de Estado; (3) veremos enseguida el estado y balance de la descentralización en Colombia: ¿mito o realidad?; (4) abordaremos posteriormente, el análisis sobre la centralización político-administrativa y su impacto en el conflicto armado en Colombia y (5) a manera de conclusión esbozaremos algunos de los retos de Colombia frente descentralización, principalmente en una situación de posconflicto.

Finalmente, de manera previa a desarrollar el plan de trabajo propuesto, se debe precisar que el método empleado en esta reflexión combina elementos de naturaleza analítica y deductiva. Por un lado, al considerar la información recopilada y estudiada, se generaron conclusiones de las normas, estudios especializados y de la doctrina más relevante sobre el particular, lo que implicó el uso del método analítico. Por otro lado, luego de haber realizado esto se efectuó una valoración de

2 "Por el cual se constituye el Sistema General de Regalías, se modifican los artículos 360 y 361 de la Constitución Política y se dictan otras disposiciones sobre el régimen de regalías y compensaciones”, reforma que tuvo control de constitucionalidad mediante la Sentencia C-317 de 2012.

3 “(...) el problema de la seguridad nacional en Colombia es ante todo un problema interno. Bajo el cerco de dos movimientos insurgentes, las FARC de raíces marxistas poco precisas y el ELN inspirado en Cuba y fundado sobre principios de la teoría de la liberación, el Estado colombiano está amenazado por una guerra militar declarada en su territorio y contra sus instituciones. Al mismo tiempo, la violencia y el comportamiento criminal relacionados con la producción y tráfico ilegal de drogas amenazan con incapacitar las instituciones estatales y la economía legal. Esta 'mezcla volátil' de insurgencia armada y narcotráfico plantea un reto directo para el Estado y hace estragos con la estabilidad interna”. (Masón, 2000, pp. 82-102). 
las principales opiniones y se hizo una reflexión crítica y propositiva. Lo anterior supuso que se empleara el método deductivo.

\section{Teorías jurídicas sobre las formas de Estado y el modelo de Estado en Colombia: de federalista a centralista}

Múltiples y variadas son las formas de Estado que se han diseminado y arraigado de este y del otro lado del Atlántico. En varias naciones del globo campea el sistema federal, por ejemplo, en los Estados Unidos de Norteamérica desde la Constitución de Filadelfia en 1787; en México, cuyo nombre oficial es Estados Unidos Mexicanos, se implantó un modelo similar al de su vecino del norte (1914), que también se siguió en la República Bolivariana de Venezuela (1999), entre otros países. Por el contrario, en otras latitudes se instaló un sistema denominado de Estado unitario, modelo de ello tenemos a países como Francia (1958), Italia (1947), Inglaterra, Perú (1993), Bolivia (2009) y, por supuesto, Colombia (1991), entre otros. En la calle del medio, como se suele decir, se encuentra España (1978), uno de los referentes obligados en cuanto a modelos de Estado, el cual, a diferencia de otros países, ha optado por el Estado autonómico o de las autonomías, en el que ya nos adentraremos más adelante. Por lo pronto, este es un paneo general de los modelos de Estado en el mundo. Ahora abordaremos cada uno de estos tres modelos para comprender mejor sus características.

El Estado federal es definido por el profesor Georges Burdeau como:

(...) el que, apareciendo como único en las relaciones internacionales, está constituido por Estados miembros que conservan ciertas prerrogativas de soberanía interna y sobre todo el Poder Legislativo. Lo que distingue estos Estados miembros de las colectividades descentralizadas del Estado Unitario es que los primeros participan en la formación de la voluntad del Estado central. (...) Además, los EstadoS miembros disponen de una competencia propia, fijada por una Constitución Federal en manera legislativa, ejecutiva y jurisdiccional (Burdeau, 1976, citado por Ramos y Rodríguez, 2009, pp. 87-88). 
Por su parte, Maurice Hauriou, enseña que el Estado Federal es aquel en el cual un súper Estado se alza por encima de otros Estados asociados (Hauriou, 1967, p. 146).

De otro lado, el autor Libardo Rodríguez ha señalado varias de sus características: primero, la unidad como persona jurídica internacional; segundo, en el ámbito interno existe pluralidad política, evidenciada en la existencia de un número plural de Estados federados; tercero, los órganos federales cumplen las tres funciones básicas del Estado (la legislativa, la ejecutiva y la judicial), de las cuales los Estados federados participan en su conformación; cuarto y, más importante, los Estados federados ejercen, con sujeción a las normas federales nacionales, funciones ejecutivas, judiciales y especialmente legislativas, que les permiten a los Estados federados expedir una Constitución Estatal y leyes de acuerdo con la competencia entre estos y el Estado federal (Rodríguez, 2008, p. 58).

La descentralización, es decir, la transferencia de funciones del centro a la periferia, es mucho mayor en este tipo de Estados, y en materias más sensibles como las propiamente legislativas (Erazo, 1991). Las repúblicas unitarias, por su parte, son principalmente centralistas ${ }^{4}$. Dicho esto, el doctrinante Georges Burdeau señala que el Estado centralista es

(...) aquel que no posee sino un solo centro de imputación política y asociación. El poder político, en la totalidad de sus atributos y funciones, depende de un titular único que es la persona jurídica del Estado. Todos los individuos colocados bajo la soberanía de este obedecen a una sola y misma autoridad, viven bajo el mismo régimen constitucional y son regidos por las mismas leyes (Burdeau, 1976, pp. 87-88).

Otros autores (Ramírez y Sánchez, 2012, pp. 23-24) que siguen a Burdeau también apuntan que el Estado unitario es:

“(...) aquel que solo posee un centro de impulsión política y gubernamental. El poder público, en la totalidad de sus atributos y funciones cuenta en él como único titular que es la persona jurídica Estado”.

\footnotetext{
${ }^{4}$ Corte Constitucional. Sentencia C-216 de 1994. M. P. Vladimiro Naranjo Mesa.
} 
En el mismo sentido, el profesor Jorge Enrique Ayala Caldas enseña que el Estado unitario

(...) supone el principio de centralización política, que se traduce en unidad de mando supremo en cabeza del Gobierno nacional, unidad en todos los ramos de la legislación, en cabeza de un Congreso y, en general, unidad en las decisiones de carácter político que tienen vigencia para todo el espacio geográfico nacional; la centralización también implica la unidad en la jurisdicción; la centralización política no es otra cosa, pues, que una jerarquía constitucional reconocida dentro de la organización jurídica del Estado (Ayala, 1999, pp. 101-102).

En ese orden de las cosas, podemos colegir que el Estado unitario es un modelo de Estado en el cual el centro -entiéndase el poder de órganos centrales radicados generalmente en la capital de la república- se encuentra fortalecido por la atribución constitucional y legal de funciones que rigen sobre todo el territorio nacional; de otra parte, y en el extremo menos privilegiado y menos poderoso, está la periferia -entendida esta como las provincias, los departamentos, los municipios, etc.-, los cuales fueron despojados de sus antiguas funciones legislativas y reglamentarias, cuando su naturaleza jurídica era de Estado miembro de la Federación, como es el caso de los Estados que conformaron los Estados Unidos de Colombia en la Constitución de 1863 y que culminó con la promulgación de la Constitución de 1886.

A su vez, es claro que la centralización es una característica de la esencia del Estado unitario, sin embargo, en Colombia esta se atenuó, de forma que la descentralización a la francesa y la autonomía de las entidades territoriales se consagraron como formas administrativas, como veremos más adelante.

Finalmente, para entender el Estado autonómico analizaremos brevemente el proceso autonómico español. Pues bien, el Estado autonómico español es producto de la escogencia del pueblo mismo entre las posibilidades descritas en la Constitución de 1978. El texto constitucional español dedica el título VIII a la "organización territorial del Estado", pero sin clarificar qué tipo de Estado es, dado que este puede ser unitario, federal, confederado o puramente autonómico. Por el contrario, la carta fundamental abre el camino a diferentes eventos, como lo señala parte de la doctrina ibérica 5 .

5 "En este título [VIII CE] no se contempla un modelo específico de Estado, sino diversas posibilidades que van desde un Estado unitario (si ningún territorio hubiera hecho uso del derecho a 
Según el profesor Francisco Balaguer Callejón, el Estado autonómico es un modelo de transición entre el regional y el federal. Un argumento poderoso para ello lo conforman las funciones legislativas que ejercen las diputaciones en nombre de la Comunidad Autónoma (CC. AA.) [art. $150 \mathrm{CE}$ ]. Si bien es cierto los "estatutos de autonomía" no son una Constitución en sentido formal, estos son una carta-guía para la CC. AA. y una garantía de la irrevocabilidad de los poderes otorgados por el Estado español, es decir, el estatuto es una constitución en sentido funcional (Balaguer, 2014, p. 131).

Es preciso recordar que, dada la influencia de asesores españoles en la hilvanación del texto constitucional colombiano de 1991, el querer de algunos constituyentes ${ }^{6}$ se vio dirigido a imitar el modelo hispánico, sin embargo, el resultado final fue otro (Rodríguez, 2014, pp. 275-302). Es decir, las diferencias capitales entre en el unitarismo y el federalismo consisten en que en el primero existe un único órgano legislativo encargado de reformar la constitución y expedir las leyes; la administración central es fuerte y asume la prestación de la mayoría de los servicios públicos, tanto administrativos como domiciliarios, por medio de su propia personería jurídica (Pactet \& Mélin-Soucramanien, 2011, p. 39); en sentido estricto, no se reconocen otras personerías jurídicas a entidades o colectividades territoriales, no existen Estados, sino departamentos, y la noción de independencia recae sobre el Estado (Vidal, 2008, pp. 49-52). Por su parte, en el segundo, los Estados miembros poseen mayor autonomía e independencia, tienen su propio Congreso, encargado de expedir leyes y en algunos casos una Constitución propia; estos a su vez participan en la toma de decisiones federales que cobijan a toda la población; cuentan personería jurídica propia y diferente de la del Estado federal; gestionan sus propios asuntos administrativos -como la prestación de servicios públicos-, entre otras funciones (Ibíd., pp. 219-221).

Ahora bien, el modelo colombiano es una hibridación del sistema unitario, similar al de 1886, es decir, centralizado políticamente, pero atenuado por el concepto

la autonomía reconocido en el art. $2 \mathrm{CE}$ ) hasta un Estado autonómico como el que se ha implantado en la práctica, muy similar al Estado federal, pasando por un Estado regional en el que se reconociera autonomía solo a determinados territorios, entre otras posibilidades”. (Balaguer, 2014, p. 121).

6 "Colombia tiene que ser un Estado autonómico, lo cual en manera alguna se opone a que sea una república unitaria. (...) un Estado autonómico, no meramente descentralizado. (...) El vocablo descentralización implica o da por supuesto que el origen del poder, su sede natural y obvia, es el centro, pero por un acto de generosidad, de largueza, es desdoblado para que llegue hasta la periferia. (...) E1 poder del Estado debe manifestarse en todas sus formas en cada lugar del territorio, tanto en el centro como en el más apartado confín”. Gaceta Constitucional n.o 19. 
de descentralización administrativa y autonomía de las entidades territoriales, sobre la cual se edifica el paradigma del Estado y la administración colombiana (Vidal, 2008, p. 218) ${ }^{7}$. Así, la centralización legislativa se mantiene en cabeza del Congreso de la República, empero la rama ejecutiva del poder público se descentraliza y las entidades territoriales adquieren un grado superior de autonomía que otrora no tenían. A este respecto, la Corte Constitucional $^{8}$ ha señalado:

(...) La autonomía, que fue introducida por la Carta de 1991 (artículos primero y 287, C.P.), denota un grado de independencia de las entidades territoriales, que se concibe como la posibilidad de autogobierno y administración de los asuntos que son de mayor interés para los entes territoriales. El grado de autonomía de los entes territoriales varía, entonces, en el tiempo, y la descentralización es un instrumento para alcanzar mayor autonomía. La autonomía territorial se encuentra ligada, además, al principio democrático y a la concepción del municipio como célula primaria del ordenamiento territorial (artículo 311, C.P.).

\section{Concepto de centralización política y descentralización administrativa, y su implantación en nuestro modelo de Estado}

La centralización en estricto rigor no reconoce ni concede ninguna clase de personalidad jurídica a las colectividades territoriales (Pactet \& Mélin-Soucramanien, 2011, p. 39). Esto significa que la única persona de derecho público sería el Estado 9 o la nación, que por medio de sus agentes y estructura se encargaría de satisfacer las necesidades de interés general. Sin embargo, en los Estados modernos, este concepto ha mutado hacia la centralización política solamente, tal como lo ha

\footnotetext{
${ }^{7} \mathrm{El}$ profesor citado atribuye la inspiración del sistema unitario y, a su vez, descentralizado al expresidente colombiano Rafael Núñez, sin embargo, no compartimos dicha posición doctrinal, puesto que los amplios poderes del Presidente de la República y la ausencia de autonomía de las entidades territoriales hacen imposible justificar esa teoría.

${ }^{8}$ Corte Constitucional. Sentencia C-957 de 2007. M. P. Dr. Jaime Córdoba Triviño.

${ }^{9}$ En el caso colombiano la Ley 153 de 1887, artículo 80, le otorgó personería jurídica a la Nación.
} 
subrayado la Corte Constitucional colombiana en múltiples sentencias ${ }^{10}$, apuntalada en la descentralización del Ejecutivo.

La centralización política atañe a lo que se conoce como un único centro de impulsión política o de creación legislativa, bien sea por medio de un congreso o un parlamento con una única Constitución y legislatura nacional, es decir, la soberanía popular es ejercida por el legislador de manera "continua" y "directa" sobre todo el conglomerado social y dentro de los límites territoriales de toda la república. Lo mismo sucede con la jurisdicción, la cual se funda sobre el principio de unidad; a su vez, desde el punto de vista administrativo se entiende que la toma de decisiones se ejerce desde los órganos administrativos centrales de la administración del Estado y por medio de su propia personería jurídica, lo que implica que las entidades situadas territorialmente fuera del centro de poder no pueden gestionar motu proprio sus asuntos de acuerdo con sus intereses sin la intervención o la autorización del nivel central ${ }^{11}$.

La Corte Constitucional ha destacado que:

(...) El Estado unitario supone el principio de la centralización política, que se traduce en unidad de mando supremo en cabeza del Gobierno nacional, unidad en todos los ramos de la legislación, en cabeza de un Congreso y, en general, unidad en las decisiones de carácter político que tienen vigencia para todo el espacio geográfico nacional; la centralización también implica la unidad en la jurisdicción. La centralización política no es otra cosa, pues, que una jerarquía constitucional reconocida dentro de la organización jurídica del Estado ${ }^{12}$.

Sin embargo, como hemos afirmado anteriormente, el Estado unitario implementado en la Constitución de 1991 tiene sus orígenes en la Revolución francesa (1789), principios que fueron reafirmados por el Imperio napoleónico en los albores del siglo XIX (Erazo, 2004, p. 217). La República de Colombia, como hoy se conoce, nació en 1832, y desde su reconocimiento como Estado soberano se ha debatido entre el centralismo y el federalismo como forma de Estado, lo cual

\footnotetext{
${ }^{10}$ Corte Constitucional. Sentencias C-496 de 1998, C-707 de 2000, C-579 de 2001, C-1258 de 2001, entre otras.

${ }^{11}$ Corte Constitucional. Sentencia C-497A de 1994. M. P. Dr. Vladimiro Naranjo Mesa.

12 Ibíd.
} 
ha generado rencillas en algunos periodos históricos, disputas tan fuertes que han llegado a socavar los delgados cimientos de la paz y la concordia nacional, desembocando en cruentas guerras civiles hasta la promulgación de la Constitución de 1886, de corte unitarista y altamente centralizadora.

Sin embargo, la nueva Constitución Política (1991) determina en su artículo 1.o que “(...) Colombia es un Estado social de derecho, organizado en forma de República unitaria, descentralizada, con autonomía de sus entidades territoriales (...)", situación que para un lector incauto o que no se ha adentrado en profundas disquisiciones jurídicas podría ser una suerte de error o contradicción. Pero lo que en realidad tenemos enfrente es un sistema hibrido o, en teoría, un modelo de centralismo político atemperado por la descentralización territorial de la administración que, junto con la autonomía de las entidades territoriales, conforman la arquitectura del Estado en Colombia.

Ahora bien, luego de haber discurrido por la noción de centralización política, debemos analizar la descentralización administrativa y, por supuesto, la autonomía de las entidades territoriales, a fin de entender sus elementos y límites tanto en la doctrina como en la jurisprudencia. La Corte Constitucional ha hecho la siguiente distinción:

(...) La autonomía es un elemento sustancial de la organización del Estado colombiano y tiene su especificidad frente a la descentralización. Por ello la autonomía de las entidades territoriales se distingue de la descentralización territorial. Mientras que la descentralización se refiere al contenido material, a las competencias y recursos asignados por la Constitución y la ley a los entes territoriales, la autonomía consiste en el margen o capacidad de gestión que el constituyente y el legislador garantizan a las entidades territoriales para que planeen, programen, dirijan, organicen, ejecuten, coordinen y controlen sus actividades, en aras del cumplimiento de las funciones y fines del Estado. Además, la autonomía es una consecuencia sine qua non de la descentralización, aunque no es exclusiva de esta. No es previsible un régimen de descentralización como forma de organización política de un Estado, en donde no haya autonomía de los entes territoriales ${ }^{13}$.

Es decir, el alto tribunal considera que la autonomía corresponde a la capacidad que poseen las entidades territoriales para gestionar los asuntos de su competencia.

${ }^{13}$ Corte Constitucional. Sentencia C-1258 de 2001. M. P. Jaime Córdoba Triviño. 
Y, de otra parte, la descentralización administrativa es la radicación de funciones en personas jurídicas diferentes al Estado, especialmente en las colectividades locales, lo que implica su reconocimiento jurídico, y estas pueden ser de carácter territorial o especializado por servicios ${ }^{14}$. Lo anterior supone el otorgamiento de personalidad jurídica, autonomía administrativa -autoridad y decisión- y autonomía financiera, entre otras. Es, en suma, el proceso de trasladar el gobierno y la gestión de los asuntos locales o periféricos de un centro de poder y llevar a la periferia (Mateo, 1985, p. 158).

La descentralización administrativa, especialmente aquella territorial, es un concepto aplicado por la mayoría de los Estados unitarios contemporáneos. Es prudente recordar que la descentralización es diferente de la desconcentración, en tanto que la primera escapa al encuadramiento dentro de la persona moral "Estado", mientras la segunda es parte integrante de este último; a su vez, las entidades descentralizadas no se encuentran dentro de la línea jerárquica administrativa, por lo cual no están sujetas a el control de tutela, como sílo están las entidades u órganos desconcentrados (Pactet \& Mélin-Soucramanien, 2011, p. 40). Entonces, la descentralización es un avance de la autogestión administrativa territorial que permite ejercer de mejor manera el poder estatal dada la inmediatez y la rapidez para la atención de los asuntos locales y la prestación de los servicios públicos dentro de un determinado espacio geográfico.

En teoría, esto es un avance importante en cuanto a la ciencia jurídica. Sin embargo, según Kalmanovitz y López (2005):

(...) Aunque en Colombia existe un Estado con larga tradición histórica (y, por lo tanto, también ha existido el imperio de la ley), este ha sido débil en términos económicos. Además, en varias fases históricas y con el conflicto intrapartidista y las luchas sociales, se ha vulnerado el Estado de Derecho y no se ha podido construir un orden consensuado robusto. La precariedad financiera del Estado y su organización centralista han dificultado su construcción y fortalecimiento local y su presencia en todo el territorio nacional, tornando ineficientes muchas de sus funciones, incluyendo la de proveer seguridad a sus asociados. Las luchas partidistas

${ }^{14}$ Corte Constitucional. Sentencia C-1258 de 2001: "La Constitución Política consagra dos modalidades de descentralización: territorial y por servicios. La primera se expresa en las entidades territoriales y permite la configuración de los niveles del Estado -nivel nacional y nivel territorial-. La segunda da lugar a las entidades descentralizadas y constituye la base de los sectores administrativos sector central y sector descentralizado- en cada uno de los niveles del Estado". 
alrededor del control del Estado, especialmente durante los años cincuenta del siglo XX, dislocaron amplias poblaciones campesinas y sobre esa base se organizaron movimientos liberales de resistencia que fueron acompañados por la organización guerrillera comunista que después se concretó con la fundación de las FARC.

Es en este punto en el que el Estado-Nación ha fallado, en la articulación, el acompañamiento y fortalecimiento de las políticas públicas que permitiesen llevar a olvidados territorios de la república los avances de la ciencia médica o el número de docentes necesarios para la atención de las poblaciones en edad de recibir instrucción educativa, incluso en los asuntos más cardinales, como la prestación de los servicios públicos domiciliarios de acueducto, electricidad, alcantarillado o saneamiento básico, que en virtud del principio de competencia residual el Estadonación es garante.

Dicho esto, consideramos que esta arquitectura, que en teoría, como hemos reseñado, está bien ideada, en la práctica no permite el desarrollo de las zonas del país que se encuentran más alejadas de centro del poder, centro cuya representación más grafica es la región montañosa colombiana, en donde se encuentran la capital (Bogotá D. C.), Medellín (capital del departamento de Antioquia), Ibagué (capital del departamento del Tolima), Cali (capital del departamento del Valle del Cauca), entre otras grandes urbes, polos de poder y desarrollo económico que gracias a su elevada población, producto de los desplazamientos masivos provocados por el conflicto armado interno que durante largos periodos han afectado especialmente las regiones suburbanas y campesinas del país, han acumulado fuerza industrial y comercial que les permite incrementar su poder tanto político como económico y una relativa paz en sus territorios, es decir, un verdadero circulo vicioso ${ }^{15}$. Confirmando esta hipótesis tenemos que:

15 "[Infortunadamente], Colombia presenta grandes desequilibrios regionales: $70 \%$ de la producción industrial y del sector terciario se origina en las cuatro principales capitales que, conjuntamente, representan el $35 \%$ de la población total. Cerca de $90 \%$ de los tributos y $70 \%$ del gasto se concentran en 40 municipios. Además, el nivel de desarrollo de los municipios presenta importantes diferencias: solo 139 municipios (13\%) tienen un nivel de desarrollo medio alto, mientras la gran mayoría, 569, presenta un desarrollo medio (52 \%) y 389, (35\%). Por otra parte, existen grandes desequilibrios e inequidades en el grado de competitividad territorial. Según un estudio reciente de competitividad, Bogotá ocupa el primer puesto con un índice de 100, seguido por Valle y Antioquia con 60, mientras el resto presenta valores menores a 40, y en los casos de Cauca, Córdoba, Cesar, Sucre y Chocó, el índice es inferior a 10”. (Devia, 2006). 
(...) como indicador de esta falta de presencia estatal, se puede mencionar que en 1995 el gasto público total alcanzó la suma de 36.2 billones de pesos, de los cuales el $86 \%$ fue ejecutado por el Gobierno central y $14 \%$ por los gobiernos departamentales y municipales. Del porcentaje ejecutado por el Gobierno central, más del 38 \% fue gastado en Bogotá y solo el 5.8 \% lo fue en la Orinoquía y la Amazonía (Fundación Social, 1998, p. 155), las cuales son regiones marginadas del desarrollo socioeconómico y donde hay conflicto armado y gran concentración de actividades de movimientos guerrilleros, paramilitares y narcotraficantes. Adicionalmente, se puede mencionar que el $77 \%$ municipios del país, donde habita el $39 \%$ de la población colombiana, han sido clasificados, desde el punto de vista socioeconómico, como precarios, frágiles o incipientes (Fundación Social, 1998, p. 395). (Orjuela, 2000).

La desigualdad está tan marcada dentro del tablero político regional que, según cifras del Departamento Nacional de Planeación, el Gobierno nacional ha distribuido a las entidades territoriales, entre 1994 y 2006, un total de $\$ 162.2$ billones de pesos. Así mismo, por Sistema General de Participaciones, se ha asignado $\$ 78.3$ billones de pesos desde 2002. Durante la década siguiente a 1994 se giraron $\$ 17.1$ billones de pesos, de los cuales, tan solo cinco departamentos recibieron el $60 \%$ de esos recursos, es decir, que entre los restantes veintisiete departamentos se dividieron el $40 \%$ de los recursos (Devia, 2006).

En suma, la falta de presencia prestacional del Estado visto como un todo ha abierto los espacios propicios para que los grupos armados ilegales crezcan y se fortalezcan en estos territorios. Es decir, la violencia en Colombia no solo es un asunto de presencia o ausencia de la fuerza pública, la violencia en Colombia es el resultado de la falta de medios de producción y ofertas económicas legales en los recónditos territorios del país. En otras palabras, la violencia es consecuencia directa de la pobreza y la inequitativa distribución de la riqueza ${ }^{16}$.

\footnotetext{
16 "La escasa presencia del Estado y sus aparatos de seguridad en amplias regiones del país refleja históricamente una débil tributación a nivel nacional combinada, como ya se ha visto, con una tributación local aún más escasa en la mayoría de municipios del país. No es tanto que el Estado no tenga presencia, sino que simplemente no se construye desde el nivel de la célula municipal con los necesarios aportes locales". (Kalmanovitz y López, 2005).
} 


\section{Estado y balance de la descentralización en Colombia: ¿mito o realidad?}

La descentralización administrativa es evidentemente necesaria, teniendo en cuenta la redistribución dispar de los recursos que se venía produciendo a lo largo del siglo XX entre regiones más pujantes y aquellas menos poderosas; sin embargo, esta había estado ferozmente represada por las élites capitalinas que detentaron el poder durante todo el antedicho siglo. Este conflicto de élites ${ }^{17}$, mayormente incrustadas en el poder político y con amplia influencia jurídica en la capital, truncó en buena medida el desarrollo de las pequeñas poblaciones de colonos que buscaban ampliar el horizonte agrícola del país, provocando de esta manera una nueva forma de violencia, esta vez ligada a la tenencia y propiedad de la tierra (La Rosa y Mejía, 2014, p. 63).

Es por esto que debemos preguntarnos sobre el estado y balance de la descentralización en Colombia, así como qué tanto hemos avanzado en la profundización del sistema y si la descentralización es un mito o una realidad.

Como ya hemos referido, en 1886, bajo la presidencia de Rafael Núñez, se expidió una Constitución centralista y con una apenas mencionada descentralización administrativa, la cual, en la práctica, no era más que un anhelo, ya que, por ejemplo, el presidente de la República tenía la facultad de nombrar a los gobernadores y estos, a su vez, a los alcaldes, entonces, la autonomía de las entidades territoriales era prácticamente nula. Con la Constitución de 1991 se esperaba un cambio trascendental en la organización territorial. No obstante, algunos autores (Hernández, 2001. p. 173; Erazo, 2004, p. 219) señalan que, si bien se estableció la descentralización y la autonomía de las entidades territoriales, en la práctica las formas del reparto del poder que habían sido establecidas desde 1886 fueron conservadas por la nueva Constitución; aunado a ello, la Asamblea Nacional Constituyente confió la expedición de la Ley Orgánica de Ordenamiento Territorial (LOOT) al Congreso de la República, y solo después de veinte años, en 2011, el legislador cumplió con su misión con la expedición de la Ley 1454 de 28 de junio del mismo año.

Durante ese periodo, que se extendió por dos décadas, el ordenamiento territorial colombiano no cambió significativamente el centralismo heredado de la antiquísima Constitución de 1886. A este respecto, Jairo Ibarra señala:

\footnotetext{
${ }^{17}$ Sobre la fragmentación de les élites en Colombia: Orjuela (2000).
} 
(...) El hecho de no existir una ley orgánica de ordenamiento territorial ha derivado en un esquema de política territorial de carácter centralista y con una serie de leyes, tales como las leyes que recortan las transferencias a las regiones, en detrimento de su desarrollo autónomo. Ese enfoque centralista es ajeno a las nuevas tendencias mundiales que le dan posibilidades a las localidades como una manera de llenar el vacío de la crisis del Estado nacional, el cual ya no tiene la capacidad para impulsar políticas macroeconómicas independientes, ya que están sujetos a decisiones económicas provenientes del exterior, y ante ello las localidades y las regiones tienen una oportunidad de impulsar sus desarrollos a través del ejercicio de su autonomía política, administrativa, fiscal y territorial. (Ibarra, 2007, pp. 37-45).

Es decir, durante cerca de veinte años y luego de la expedición de la nueva Constitución, el único cambio en la estructura territorial fue la supresión las intendencias y comisarias, pero se conservaron los departamentos, municipios y los distritos, pero se tuvo una novedad: los territorios indígenas (Duque, 2012). Con la expedición de la LOOT, que desarrolló los preceptos constitucionales del artículo 286, por medio de la expedición de una ley orgánica se autorizó darles el carácter de entidades territoriales a las regiones y a las provincias, es decir, dos décadas después se dio vía libre a la creación de entidades territoriales que profundizasen la descentralización, lo cual bien podría ser considerado como una omisión legislativa ${ }^{18}$. Podemos ofrecer varias explicaciones de tipo político para explicar esta morosidad del legislador ${ }^{19}$, pero solo una relevante jurídicamente, y es que la propia Constitución le impuso una carga mayor a su trámite de aprobación, a saber, el de una ley orgánica que necesita el voto de la mayoría absoluta de una y otra cámara (art. 151 y 288 C.N.), lo que entorpeció largamente los intentos de configuración de la Ley.

A pesar de ello, en la actualidad contamos con ocho figuras introducidas por la LOOT, algunas en desarrollo de la Constitución y otras producto de la innovación del legislador, estas son las regiones administrativas y de planificación (RAP); la región administrativa y de planificación especial (RAPE); las regiones de planificación y gestión; las asociaciones de departamentos; las provincias administrativas

\footnotetext{
${ }^{18}$ Sobre este aspecto véase: Corte Constitucional. Sentencia C-489 de 2012. M. P. Dra. Adriana María Guillén Arango.

${ }^{19}$ Los proyectos de Ley de Ordenamiento Territorial fueron los siguientes: n.o 130, No. 191 y n.o 195 de 1995, n.o 103 de 1996, n.o 021 de 1997, n.o 128 de 1999, n.o 077 de 2000 y n.o 041 de 2001. Ninguno de ellos triunfó debido a intereses políticos principalmente que no permitieron los consensos necesarios para su aprobación.
} 
y de planificación; las asociaciones de las áreas metropolitanas; las asociaciones de municipios y distritos; las asociaciones de distritos especiales.

La mayoría de ellas se podrán establecer para prestar servicios públicos, ejecución de obras y proyectos de desarrollo económico y social (Duque, 2012).

De otra parte, el Gobierno nacional, con el ánimo de ejercer mayor control y combatir la corrupción imperante en los municipios y departamentos petroleros y mineros, decidió "recentralizar" las regalías. Por medio de una iniciativa de Acto Legislativo (AL), el Gobierno modificó el contenido de los artículos 360 y 361 de la Constitución Nacional, aprobado mediante AL 05 de 201, por medio de los órganos colegiados de administración y decisión y el Sistema General de Regalías, un acto que a los ojos de los pueblos que han sufrido el "boom" minero-petrolero es una injusticia que incluso violenta los pilares sobre los cuales se erige nuestra Constitución Política, razón por la cual existen en curso y así mismo ya han sido falladas varias demandas en contra el AL con el argumento de que por medio de este el Congreso ha sustituido la Constitución, entre otros (Estupiñán, 2012. p. 244 y ss.).

Así las cosas, la descentralización está lejos de ser un mito, pero en una correlativa distancia de ser una realidad. Pasos enormes se han dado desde la década de los ochenta ${ }^{20} \mathrm{y}$ en la subsiguiente década de los noventa con la expedición de la Constitución Política, y más recientemente al inicio de la segunda década del siglo XXI, dada la expedición de la Ley de Ordenamiento Territorial (Ley 1454 de 28 de junio de 2011). Empero, esto no ha sido suficiente para permitir la articulación de todo el territorio nacional bajo la egida de la descentralización administrativa que hemos venido implementando.

\section{La centralización político-administrativa y su impacto en el conflicto armado en Colombia}

La centralización político-administrativa ha participado en la generación, el establecimiento y el aumento de la violencia en tres escenarios históricos. El

20 "El soporte legislativo de ese proyecto modernizador está consagrado en el acto Legislativo n.o 1 de 1986 (elección popular de alcaldes, y su Ley Reglamentaria n.o 11 de 1986). A nivel regional se adoptan medidas sobre el régimen departamental (Ley 03 de 1986) y sobre planificación regional (Ley 76 de 1985), y con el propósito de incrementar los fiscos departamentales y municipales ya se habían expedido la Ley 14 de 1983 y la Ley 12 de 1986 para incrementar los montos de las transferencias desde el gobierno central hacia el nivel municipal”. (Ibarra, 2007). 
primero de ellos es en el periodo subsiguiente a la Independencia, caracterizado por guerras internas entre liberales y conservadores, tanto por el poder como por el modelo de Estado que debiese implantarse en la nueva república, y que tendría como límite temporal y resolución cuasi definitiva a la disputa, la expedición de la Constitución de 1886 (López, 1999). El segundo periodo es aquel posterior a la Constitución de 1886, caracterizado por una implacable centralización del poder al ser un país gobernado casi enteramente desde Bogotá, aunado a una inexistente participación política y a una pugna incesante entre los dos partidos tradicionales, el liberal y el conservador (Bushnell, 1994, pp. 276-292). Y el tercero es el actual periodo regido por la Constitución Política de 1991, en el que, a nuestro juicio, existe una descentralización aún muy joven y cada vez más frágil, lo que permite el desarrollo desigual y una abismal diferencia al acceso a los servicios públicos entre departamentos y municipios, incluso vecinos.

Por cuestiones prácticas y las circunstancias precisas de este documento, solo nos referiremos al tercer escenario. Así las cosas, la violencia actual es heredada del siglo XX, por tanto, es una consecuencia directa de las rencillas partidistas que luego se trasladaron al ejercicio del poder, el cual devino centralista ya que, a todas luces, estaba justificado en el temor de perder el control político y ejecutivo de una parte del territorio. El control partidista se logró asegurar por medio de la designación directa de los gobernadores de departamento por parte del presidente de la República y de los alcaldes por parte de los gobernadores, situación que solo cambió hasta 1986, cuando se autorizó la elección popular de alcaldes ${ }^{21}$, y por medio de la Constitución de 1991, que autorizó la elección popular de gobernadores, cuya primera elección se hizo en 1992.

Es decir, las decisiones que concernían a la planeación, ejecución y financiación de obras cruciales para el desarrollo de las regiones se tomaban en un reducido espacio de la capital del país, lejos de las llanuras del Vichada o el Casanare, de los imponentes desiertos de la Guajira, o de las húmedas y frondosas selvas del Amazonas o el Catatumbo, en donde el ardor de la violencia aún subsiste muy de la mano del abandono estatal.

Actualmente, en Colombia operan los grupos insurgentes de las FARC-EP (Fuerzas Armadas Revolucionarias de Colombia, autodenominadas Ejército del Pueblo), el ELN (Ejército de Liberación Nacional), EPL (Ejército Popular de

\footnotetext{
${ }^{21}$ Por medio del Acto Legislativo n.o 01 de 1986.
} 
Liberación) y los grupos paramilitares de extrema derecha AUC (Autodefensas Unidas de Colombia), los cuales se encuentran emplazados en alrededor de 360 municipios en el país (CERAC, s. f.). Bien lo describen La Rosa y Mejía:

(...) En un país de regiones, con una geografía que desafía todo intento de unificación, la violencia fue un fenómeno que mostró con claridad las debilidades del Estado colombiano. El gobierno estaba a todas luces restringido a la plaza de Bolívar y a otras plazas centrales en las capitales regionales del país. La gente del campo no tenía incentivo para obedecer leyes arbitrarias, irradiadas desde una capital distante y escritas por políticos que no entendían la vida rural. Cuando el Partido Liberal decidió no presentar un candidato a las elecciones de 1950, la política se volvió algo más que concursos electorales y gobernanza: para los liberales que no tenían participación alguna en el aparato político oficial, la violencia parecía ser el único medio de intervención política. Por lo tanto, los asesinatos por venganza, el robo de ganado y las largas disputas familiares y territoriales determinaron la realidad de extensas partes de la Colombia andina y rural, y el distante gobierno era a la vez incapaz y reticente a poner fin a todo esto. (La Rosa y Mejía, 2014, p. 114).

Así las cosas, la centralización política y administrativa está estrechamente vinculada con la violencia, dado que en un país en donde unos pocos gobiernan según los intereses de cuatro o cinco departamentos capitales, y en donde la división administrativa no es otra cosa que una manera de dividir las fronteras naturales o culturales, mas no un móvil para la inversión racionalizada de los recursos públicos, no puede desarrollarse una paz duradera, puesto que allí en donde el Estado no llega se ciernen las sombras del narcotráfico y no se acallan los tambores de la guerra irregular ${ }^{22}$.

22 "Definitivamente no hay una sola Colombia: existen dos Colombias. La Colombia urbanizada, conformada por las ciudades como Bogotá, Medellín, Cali y Bucaramanga en la región Andina, y Barranquilla; es la Colombia moderna, en condiciones de poder integrarse a las nuevas corrientes económicas y culturales de la globalización; y está la otra Colombia, de los colonos, campesina, de los indígenas, y de negros, en la que proliferan los cultivos ilegales, la ganadería extensiva y la violencia de mil rostros que genera el drama de los desplazados. Esta Colombia en la que agentes distintos al Estado se disputan el territorio por el control de las rutas de la coca y de los recursos tanto naturales como públicos por la ausencia total del Estado (...)”. (Orjuela, 2000, pp. 103-116). 
Al respecto, vale la pena citar a la profesora Ann Masón, quien con franqueza resume parte de los múltiples problemas que aquejan a Colombia, incluyendo la centralización:

(...) La autoridad, reciprocidad y responsabilidad que constituyen la legitimidad vertical han sido erosionadas por la corrupción, la acumulación de las diferencias económicas, el clientelismo, el regionalismo y la gran ineficacia del sistema. Dentro de la sociedad hay un escaso consenso sobre la idea unificadora de Colombia y muchos sectores de [esta] combaten activamente, y en muchos casos con violencia, la legitimidad y principios organizativos fundamentales del Estado. Las instituciones gubernamentales son corruptas, ineficientes y excluyentes. El sistema político democrático no funciona en muchas jurisdicciones debido a amenazas y al terrorismo de insurgentes y paramilitares, y en el nivel nacional es entorpecido por el clientelismo, la corrupción y la precaria responsabilidad pública. El sistema legal colombiano no suministra justicia sistemáticamente ni ha logrado contener la reciente explosión de ilegalidad (Pardo, 2000, p. 76). La Policía y las instituciones militares son incapaces de mantener el orden público y de ofrecer seguridad para la población civil. El suministro de servicios públicos básicos ha sido seriamente deteriorado por la devastadora recesión económica. Por actos tanto de omisión -la inhabilidad de proteger a sus ciudadanos de las masacres de criminales, la guerrilla y los paramilitares- y comisión -las violaciones a los derechos humanos cometidas por el Ejército colombiano-, Colombia ha perdido el monopolio del uso legítimo de la fuerza. Extensas áreas del país no cuentan con presencia del Gobierno central ni con protección policial, mientras que los productores de drogas, las fuerzas guerrilleras y los paramilitares compiten violentamente por el control de regiones estratégicas.

Pese al panorama descrito con anterioridad, cabe resaltar que en 1991 la democracia colombiana se reafirmó; el ejercicio del poder popular fue devuelto al constituyente primario, y junto a este un nuevo paradigma se erigió. Hoy la teoría de la descentralización administrativa campea por todo el territorio, pero en la práctica se muestra como un reto para esta y las futuras generaciones: no podemos olvidar que Roma no se construyó en un solo día, Colombia tampoco. La descentralización de la mano de una nueva ley anticorrupción (Ley 1474 de 12 de junio de 2011) y un proceso de paz en marcha, aunado a un aumento histórico de la inversión pública 
en la red vial (DPN, 2014) -vías 4G y corredores para la prosperidad- esperan cambiarle el cariz a Colombia en la próxima década.

\section{Los retos de Colombia frente a la descentralización}

Finalmente, con el ánimo de enriquecer el debate sobre la descentralización administrativa, es preciso señalar algunos de los retos y desafíos de la república y su impacto en una Colombia inmersa aún en un conflicto armado interno, o bien, en una Colombia atravesando el posconflicto.

El primer reto de la república es la profundización de la descentralización. Esta profundización debe ser tanto estructural como funcional, es decir, esta no solo tiene que concentrarse en la promoción o la creación de nuevas entidades territoriales, como las regiones y asociaciones según lo establece la LOOT (Devia, 2006), sino también ha de estar acompañada de una mayor transferencia de funciones y de recursos del Estado a las entidades territoriales (Iregui, 2001).

El segundo desafío es encontrar los instrumentos de fomento de la tributación de las entidades territoriales (ET) ya existentes. Para lograr dicho objetivo, el Congreso de la República podría crear nuevos impuestos de estirpe facultativa, dotando a las ET de la posibilidad de resolver, teniendo en cuenta la conveniencia regional, cómo y en qué momento estos entrarían a funcionar y los periodos de suspensión si a ello hubiere lugar (artículo 338 C.N.). Bien lo señala la profesora Liliana Estupiñan Achury cuando se refiere a la creación del modelo entre 1991 y 1994: “(...) En materia de descentralización fiscal, el plan es reiterativo al señalar que descentralización sin recursos es un fracaso, pero más aún, descentralización sin recursos propios” (Estupiñán, 2012, p. 172).

Tercero, fortalecer la lucha contra la corrupción. Según datos gubernamentales, la corrupción acumulada desde 1991 hasta 2010 alcanzó la cifra récord de 189 billones de pesos en apenas diecinueve años. Es por esto que una lucha frontal contra la corrupción, especialmente en las entidades territoriales, mejoraría los indicadores de eficiencia y, de esta manera, la canalización de los recursos hacia las poblaciones más vulnerables, las cuales están más propensas de caer en la violencia. Esto se lograría, por ejemplo, llevando los servicios públicos a los sectores periféricos de las ciudades más grandes del país y hasta los municipios más alejados del centro del país (Estupiñán, 2012, p. 177). 
Cuarto, como política de Estado, se debería privilegiar la inversión económica periférica, es decir, aquella que se genera fuera de las grandes urbes, lo cual, además de creación de condiciones sociales óptimas en municipios y departamentos propensos a la violencia y al narcotráfico, también permitiría la descongestión y evitaría el hacinamiento en las grandes ciudades del país. Esto crearía empleos, y la presencia del Estado evitaría, estando en un estado de posconflicto e incluso aún en conflicto, que los grupos tuvieran la facilidad de reclutar menores con discursos sobre la orfandad a la que el Estado, que les cobra impuestos, les obliga a vivir.

\section{Conclusiones}

Luego de haber discurrido por difíciles entresijos tanto jurídicos como sociológicos y económicos, podemos deducir con veracidad que la centralización político-administrativa, desde sus inicios, incluso cuando era una mera postura de una de las élites criollas posindependentistas, ha contribuido en buena medida al escalamiento del conflicto armado colombiano, siempre desde una perspectiva diferente, pero con gran influencia sobre el conflicto. Inicialmente, en los bandos unitarista y federalista, del libertador Simón Bolívar y del prócer Francisco de Paula Santander (Bushnell, 1994, p. 98), respectivamente; luego, a lo largo de las cruentas y numerosas guerras civiles (Saa, 1984, p. 30) de los siglos XIX y XX, auspiciadas por los partidos Liberal y Conservador; y, más recientemente, el conflicto armado interno producto tanto de los odios y exclusiones políticas entre los partidos tradicionales como del abandono prestacional y presencial del Estado, además de la presencia del narcotráfico y la lucha por la tenencia de la tierra.

Colombia es un país de una férrea tradición centralista (Estupiñán 2012, pp. 105-106) pese a que vivió gobiernos federales a lo largo del siglo XIX. Con más de cien años de vigencia, la Constitución de 1886 marcó para siempre tanto a la sociedad como a las instituciones, que son parte de la historia y que a su vez la moldean. Por tanto, a pesar de que el constituyente en 1991 pretendió virar sobre una descentralización administrativa profundizada por la autonomía de las entidades territoriales, dicho intento se frustró, merced de la incapacidad del Estado como por la ausencia de una ley de ordenamiento territorial que reglamentase el asunto. Como consecuencia de ello existe aún en el siglo XXI, en la Modernidad, un vacío que el Estado no ha podido ni ha sabido ocupar, y en el que la pobreza, le ausencia de justicia, de salud y educación han sido aprovechada por los grupos insurgentes 
como las FARC, el ELN, los grupos paramilitares y las bandas criminales (bacrim) para hacerse con parte del territorio nacional. Por tanto, no podemos afirmar que Colombia sea un Estado plenamente descentralizado administrativamente, pero tampoco podemos negar los significativos avances que viene dando el país a este respecto, pues Colombia es un país en vía de construcción.

Dado que muchos de los municipios y departamentos no pueden satisfacer las necesidades básicas de sus habitantes, aunado a un grave problema de narcotráfico, tenencia y propiedad de los medios de producción y a una corrupción impune, las condiciones están dadas para la perpetuación del conflicto (Orjuela, 2000 y Masón, 2000). Es por ello que urge la presencia del Estado por medio de sus entidades descentralizadas.

Así las cosas, podemos colegir con mediana claridad que la centralización (Kalmanovitz y López, 2005) en Colombia ha impedido al Estado llegar a las zonas más alejadas de las grandes ciudades colombianas, en donde los grupos ilegales han suplantado al Estado y ejercen casi en totalidad sus funciones, lo que ha generado lamentablemente una profundización de la violencia existente o, lo que es peor, el nacimiento de una nueva violencia en dichos territorios.

Finalmente, y a título de corolario, se puede señalar que la descentralización en Colombia está lejos de ser un mito, pero en una correlativa distancia de ser una realidad. Es, en verdad, un reto inconcluso que se convierte en un desafío para una situación de posconflicto una vez lograda la tan anhelada paz social.

\section{Referencias}

Asamblea Nacional Constituyente. Gaceta Constitucional. № 19, 19 de febrero de 1991. Ayala,J. E. (1999). Elementos de derecho administrativo general (1.a ed.). Bogotá: Ed. Doctrina y Ley. Balaguer, F. (Coord.). (2014). Introducción al derecho constitucional (3.a ed.). Madrid: Ed. Tecnos. Burdeau, G. (1976). Droit Constitutionnel et institutions politiques (1.a ed.). Paris: Librairie generale de droit et de jurisprudence R. Pichon et R. Durand-Auzias.

Bushnell, D. (1994). Colombia: una nación a pesar de si misma. De los tiempos precolombinos a nuestros días (Trad. Claudia Montilla). Bogotá: Planeta Colombiana Editorial S. A.

Centro de Memoria, Paz y Reconciliación. (s. f. a). Los pactos de la Uribe FARC-EP (1984 y 1986) y diálogo nacional con el M19, EPL y ADO (1984). Recuperado de http://goo. g1/WguaMm

Centro de Memoria, Pazy Reconciliación. (s.f.b). El cagúan. Recuperado dehttp://goo.gl/VtGK0D 
Centro de Recursos para el Análisis de Conflictos (CERAC). (s. f.). Datos del conflicto armado de Colombia. Recuperado de http://goo.gl/LiO3Yr

Constitución Política de Colombia de 1991.

Corte Constitucional. Sentencia C-216 de 1994. . Sentencia C-497A de 1994. Sentencias C-496 de 1998. . Sentencias C-707 de 2000. Sentencias C-579 de 2001. Sentencias C-1258 de 2001. Sentencia C-957 de 2007. Sentencia C-317 de 2012. Sentencia C-489 de 2012.

Departamento Nacional de Planeación (DPN). (2014). La infraestructura en el Plan Nacional de Desarrollo 2014-2018. Cartagena: DPN.

Devia, S. P. (2006). La descentralización en Colombia: un reto permanente. IB. Revista de Información Básica, 1(2). Recuperado de http://goo.g1/B6HaVf

Duque, N. (2012). Particularidades de la ley orgánica de ordenamiento territorial. Análisis Político, 25(76), 175-190.

Erazo, Y. (2004). El fracaso de la autonomía territorial esbozada en la constitución de 1991. Criterio Jurídico, 1(4), 217-230.

Estupiñán, L. (2012). Desequilibrios territoriales. Estudio sobre la descentralización y el ordenamiento territorial colombiano: una mirada desde el nivel intermedio de gobierno. Bogotá: Universidad del Rosario y Ed. Doctrina y Ley.

Hauriou, A. (1967). Droit constitutionnel et institutions politiques. Paris: Ed. Montchrestien. Hernández, A. (2001). Ordenamiento y desarreglo territorial de Colombia. Bogotá: Universidad Externado de Colombia.

Ibarra, J. (2007). Reflexiones sobre el ordenamiento territorial en Colombia. Justicia Juris, 7, 37-45.

Iregui, A. M. (2001). Análisis de la descentralización fiscal en Colombia. Recuperado de http:// goo.g1/UtpSgf

Kalmanovitz, S. y López, E. (2005). Tierra, conflicto y debilidad del Estado en Colombia. Observatorio de la Economía Latinoamericana, 44. Recuperado de http://goo.g1/15vztX

La Rosa, M. J. y Mejía, G. R. (2013). Historia concisa de Colombia (1810-2013). Una guía para lectores desprevenidos. Bogotá: Ministerio de Cultura, Universidad del Rosario y Pontificia Universidad Javeriana.

Ley 153 de 1887. Por la cual se adiciona y reforma los códigos nacionales, la ley 61 de 1886 y la 57 de 1887, Diario Oficial n.o 7151 y 7152 de agosto 28 de 1998. 
Ley 1454 de 2011. Por la cual se dictan normas orgánicas sobre ordenamiento territorial y se modifican otras disposiciones, Congreso de la República, Diario Oficial n.o 48115 de 29 de junio de 2011.

Ley 1474 de 2011. Por la cual se dictan normas orientadas a fortalecer los mecanismos de prevención, investigación y sanción de actos de corrupción y la efectividad del control de la gestión pública, Congreso de la República, Diario Oficial n.o 48128 de julio 12 de 2011.

López, M. (1999). Frente a la guerra: la ética. Nova E Vetera. Boletín del Instituto de Investigaciones de la ESAP, 33, 33-38. Recuperado de http://www.bdigital.unal.edu.co/47364/1/ frentealaguerra.PDF

Manrique, A. (2010). Fundamentos de la organización y del funcionamiento del Estado Colombiano (2.a ed.). Medellín: Centro Editorial Universidad del Rosario y Biblioteca Jurídica Diké.

Masón, A. (2000). La crisis de seguridad en Colombia: causas y consecuencias Internacionales de un estado en vía de fracaso. Colombia Internacional, 49/59, 82-102. Recuperado de http://goo.g1/L2X2E7

Mateo, R M. (1985). Manual de derecho administrativo (9.a ed.). Madrid: Instituto de Estudios de Administración Local.

Orjuela, L. J. (2000). La debilidad del Estado colombiano en tiempos del neoliberalismo y el conflicto armado. Revista Colombia Internacional, 49/50, pp. 103-116.

Pactet, P., \& Mélin-Soucramanien, F. (2011). Droit constitutionnel (30.a ed.). Paris: Ed. Sirey

Ramos, J. y Rodríguez, C. H. (2009). Estructura y organización del Estado constitucional colombiano. Bogotá: Ed. Ibáñez.

Ramírez, J. y Sánchez, J. W. (2012). Estructura del Estado. Bogotá: Ed. Librería Ediciones del Profesional.

Registraduría Nacional del Estado Civil.

Rodríguez, L. (2008). Derecho administrativo general y colombiano. (16.a ed.). Bogotá: Ed. Temis.

Rodríguez, J. P. (2014). El principio de la autonomía territorial de los municipios y departamentos en Colombia, análisis y perspectivas desde la jurisprudencia de la corte constitucional 1992-2012. Revista Summa Iuris, 2(2), 275-302.

Saa, E. (1984). El proceso de la Constitución de 1886 y don Rafael Núñez. Popayán: Universidad del Cauca.

Vidal, J. (2008). Derecho administrativo. Bogotá: Legis. 